\title{
Is Technology at the Service of Humankind?
}

\author{
Francisco Cristovão Lourenço de Melo ${ }^{1, *}$
}

Melo FCL (D) https://orcid.org/0000-0002-4181-1964

\author{
How to cite \\ Melo FCL (2020) Is technology at the service of humankind? \\ J Aerosp Tecnol Manag, 12: e0320. https://doi.org/10.5028/ \\ jatm.v12.1121
}

The answer is not a trivial one.

While technology has allowed the human race to live longer, it has given us weapons of mass destruction. It is a fact that technology has improved communications but, on the other hand, it has increased the distance regarding interpersonal relationships. Although nowadays it is quite easy to find evidence to solve previous unsolved problems, we live in the society so soaked by fake news that in some cases, only an artificial inteligence (AI) can detect it.

Deny the technological advance and its importance to our new concept of human society means to be thrown into the abyss of failure whose impact for humankind will be the loss of productive capacity and thus the endangering of our survival.

The $21^{\text {th }}$ century conundrum is how can humans evolve using those brand new and disruptive technologies that pop up every day and still improve their quality of life for the best? How can we, as a race, improve production, implement industry 4.0 and information technology in services without creating chaos at work or at our every day life? These are some of questions for which answers we still can't find answers.

We are living in a period in the human history where several disruptive technologies are materializing and humanity does not realize how to understand, absorb and, most importantly, take advantage of them for our welfare. So far, what we see is the opposite.

Many authors say we are in the age of knowledge. But are we?

If we analyze at cold blood. What we see is a period of uncertainty. On this age of knowledge, we have more questions than answers. Every door that science and technology open becomes a sea of new possibilities of questions and answers.

In the aeronautical sector, the drone technology is no longer a trend but a reality. But a question remains unanswered; will the advance of drones' tech eliminate the need for pilots in the medium and long term?

Meanwhile, in the aerospace sector, there has been a massive proliferation of engineering teams designing and building small satellite and CubeSats capable of more and more data acquisition. As these tech evolve, could it mean end of the large satellites?

Of all the urgent problems that humanity has to deal with, one that stands out, is global warming. Global climate has been changing... and we need to do something about it because doing nothing threatens the survival of the human race.

It is not the objective of this editorial to discuss why global warming is happening or what we can do to stop it, but one thing is sure, the solution will involve the aerospace sector - from launch vehicles that put advanced climatic observation satellites into orbit to monitor the planet 24 hours a day to new and bold alternatives, like colonization of other planets and satellites like the Moon and Mars.

Finally, I conclude this editorial by calling on the authors to research and publish articles that guide us on how science, technology and management of the aerospace sector can effectively contribute to the control of global warming and its effects.

\footnotetext{
1. Departamento de Ciência e Tecnologia Aeroespacial - Instituto de Aeronáutica e Espaço - Escritório de Estratégias Tecnológicas - São José dos Campos/SP Brazil

Correspondence author: francisco.frapi@gmail.com

Received: Dec 16, 2019 | Accepted: Dec 31, 2019
} 


\section{REFERENCES}

Mbat JP (2013) Science, technology, and the future of man. IOSR Journal of Humanities and Social Science (IOSR-JHSS) 8(2):1-9. https://doi.org/10.9790/0837-0820109

Bostrom N (2007) The Future of Humanity. New York: Nick Bostrom's Home Page; [accessed 2019 Dec 17]. https://www. nickbostrom. com/papers/future.pdf

Salmi J, Millot B, Court D, Crawford M, Darvas P, Golladay F, Holm-Nielsen L, Hopper R, Markov A, Moock P, et al. (2002) Constructing knowledge societies: New challenges for tertiary education. Washington: The International Bank for Reconstruction and Development/ The World Bank.

ISECG (2018) The Global Exploration Roadmap. National Aeronautics and Space Administration; [accessed 2019 Dec 17]. https://www. nasa.gov/sites/default/files/atoms/files/ger_2018_small_mobile.pdf

Millar C, Lockett M, Ladd T (2017) Disruption: Technology, innovation, and society. Technol Forecast Soc Change 129:254-260. https:// doi.org/10.1016/j.techfore.2017.10.020 